\title{
A predictive model for the formation potential of dichloroacetamide, a nitrogenous disinfection by-product formed during chlorination
}

\author{
W. H. Chu N. Y. Gao $\cdot$ D. Q. Yin • \\ Y. Deng $\cdot$ M. R. Templeton
}

Received: 15 July 2011/Accepted: 10 December 2011/Published online: 4 August 2012

(C) CEERS, IAU 2012

\begin{abstract}
Nitrogenous disinfection by-products have increasingly become a public health concern in the drinking water industry because they have been found to be more geno- and cytotoxic than most of the currently regulated disinfection by-products. Dichloroacetamide, a nitrogenous disinfection by-product which is formed during chlorination in water treatment, has increasingly received attention due to its elevated genotoxicity and cytotoxicity relative to the currently regulated disinfection by-products. In this study, a power function model with parameters of dissolved organic nitrogen, dissolved organic carbon, bromide, soluble microbial products, and aromatic proteins was developed to successfully predict dichloroacetamide formation potential. The inclusion of soluble microbial product and aromatic protein into the model significantly improved the prediction, suggesting that soluble microbial product and aromatic protein play a significant role in the formation of dichloroacetamide. Additionally, the performance of the predictive model appeared to be somewhat affected by the characteristics of raw water used to develop the model.
\end{abstract}

W. H. Chu · N. Y. Gao (凶) · D. Q. Yin

State Key Laboratory of Pollution Control and Resources Reuse,

College of Environmental Science and Engineering,

Tongji University, Shanghai 200092, China

e-mail: feedwater@126.com

\section{Y. Deng}

Department of Earth and Environmental Studies,

Montclair State University, Montclair, NJ 07043, USA

M. R. Templeton

Department of Civil and Environmental Engineering, Imperial College London, London SW7 2AZ, UK
Keywords Aromatic protein - Drinking water . Formation potential prediction - Dissolved organic carbon . Soluble microbial products

\section{Introduction}

Nitrogenous disinfection by-products (N-DBPs) which are formed during chlorination in drinking water treatment are receiving increasing attention because they have been demonstrated to be more genotoxic and cytotoxic than the currently regulated DBPs (Richardson et al. 2007). Among the N-DBPs, five haloacetamides (HAcAms) were identified in tap water in a US nationwide DBP occurrence study (Krasner et al. 2006). HAcAms have much higher genoand cytotoxicity than most of the other N-DBPs (Plewa et al. 2008). Of these HAcAms, dichloroacetamide (DCAcAm) has been most commonly detected in water samples in several countries including the United States and China (Richardson et al. 2007; Chu et al. 2011). To fully understand the occurrence of DBPs (Imo et al. 2007) and develop DBP minimization strategies (Mesdaghinia et al. 2005), it is essential to comprehend the formation of DBPs in water.

Over the past 30 years, at least 118 predictive models have been developed to predict the formation of various DBPs, presented in 48 scientific publications (Chowdhury et al. 2009). Using a power function has been one of the modeling methods to estimate the relative contributions of relevant parameters to the formation of carbonaceous DBPs (C-DBPs) (Harrington et al. 1992; Sohn et al. 2001; Semerjian et al. 2009). These models have improved the understanding of C-DBP formation, provided a foundation to perform toxicological and epidemiological risk assessment, and offered valuable information regarding the 
minimization of C-DBPs. Most of these reported models have employed dissolved organic carbon (DOC), disinfectant dose, $\mathrm{pH}$, temperature, and reaction time as the key parameters. Chen and Westerhoff (2010) recently introduced dissolved organic nitrogen (DON) as an input variable into a prediction model to successfully compute the formation potential (FP) of haloacetonitriles (HANs), suggesting that $\mathrm{N}$-containing organic matter is an important HAN precursor. Furthermore, recent studies (Chu et al. 2010a, b) have reported that the characteristics of N-containing organic matter, rather than the DON level, determined the formation of HAcAms.

Specifically, the findings revealed that soluble microbial products (SMP) and aromatic protein (AP) compounds, characterized by fluorescence excitation-emission matrix (EEM) spectra, play a significant role in DCAcAm formation. These efforts motivated us to develop a DCAcAm FP prediction model, in which EEM spectra parameters of SPM-like and AP-like compounds were incorporated. To the best of our knowledge, this study is the first effort to build a predictive model for HAcAm FP. This study was carried out in the State Key Laboratory of Pollution Control and Resources Reuse of Tongji University, China in 2008-2011.

\section{Materials and methods}

Materials and samples

DCAcAm (98.5 \%) and TCAcAm (99 \%) standards were obtained from Alfa Aesar (Karlsruhe, Germany). Extractant ethyl acetate was obtained from Fisher Scientific (Waltham, USA). All the other chemicals and reagents were purchased from Sinopharm (Shanghai, China). Most water samples were collected on the 15th day of every month from the Huangpu River, which is the water source for several major surface water treatment plants (WTPs) in Shanghai, China. All the other samples were collected from Lake Taihu (containing high DON and low bromide) and Qingcaosha Reservoir (containing low DON and high bromide). Lake Taihu is the third largest freshwater lake and the potable water source of many cities and towns in eastern China. Qingcaosha Reservoir is located in the estuary of the Yangtze River and supplies $7.19 \times 107 \mathrm{~m}^{3} /$ day water to meet the drinking water demand of approximately 10 million people in Shanghai. Once collected, each sample was immediately filtered through a pre-rinsed $0.7-\mu \mathrm{m}$ glass filter membrane $(\mathrm{GF} / \mathrm{F}, 0.7 \mu \mathrm{m}$, Whatman, UK) and then stored in the dark at $4{ }^{\circ} \mathrm{C}$ until use. The quality of this raw water is shown in Table 1. Analysis of the collected raw water samples showed that the background DCAcAm level was undetectable.
Analytical methods

Bromide, DOC, DON, three-dimensional fluorescence EEM spectra, and DCAcAm FP were analyzed using methods explained in detail previously (Huang et al. 2008; Chu et al. 2010a, b). DCAcAm was analyzed using liquidliquid extraction and gas chromatograph/mass spectrometry (Shimadzu-QP2010, Japan) (Chu and Gao 2009).

Model development and statistical analysis

The chlorine dose is almost proportional to the DOC value of water samples in DCAcAm FP test (Chu et al. 2010b). All other disinfection conditions, i.e., reaction time $(24 \mathrm{~h}), \mathrm{pH}$ (7.5), and temperature $\left(24^{\circ} \mathrm{C}\right)$, were kept constant in all trials. The DOC, DON, $\mathrm{Br}^{-}$, SMP and AP were the other power function model parameters. The power function prediction model of DCAcAm FP is shown in Eq. (1) below:

$$
\begin{aligned}
\text { DCAcAm FP }= & a \times[\mathrm{DON}]^{b} \times[\mathrm{DOC}]^{c} \times\left[\mathrm{Br}^{-}\right]^{d} \\
& \times[\mathrm{SMP}]^{e} \times[\mathrm{AP}]^{f}
\end{aligned}
$$

where $a$ is a lumped parameter representing the disinfection conditions including disinfectant dose, reaction time, $\mathrm{pH}$, and temperature, unitless; DON is the mass concentration of dissolved organic nitrogen, $\mathrm{mg} / \mathrm{L}$; DOC is the mass concentration of dissolved organic carbon, $\mathrm{mg} / \mathrm{L} ; \mathrm{Br}^{-}$is the mass concentration of bromide, $\mu \mathrm{g} / \mathrm{L}$; SMP is the maximum peak intensity of SMP-like peak in the EEM spectra, $\mathrm{mV}$; AP is the maximum peak intensity of AP-like peak in the EEM spectra, $\mathrm{mV}$; and, $b, c, d, e$, and $f$ are the powers of DON, DOC, $\mathrm{Br}^{-}$, SMP, and AP, respectively. The content of SMP-like and AP-like substances can be indirectly estimated by their fluorescence EEM spectra. Chen et al. (2003) developed a fluorescence regional integration method, in which the EEM spectra were summarized into five regions, including SMP-like $\left(\lambda_{\mathrm{ex}}>250 \mathrm{~nm}, \lambda_{\mathrm{em}}<380 \mathrm{~nm}\right)$ and AP-like $\left(\lambda_{\mathrm{ex}}<250 \mathrm{~nm}, \lambda_{\mathrm{em}}<380 \mathrm{~nm}\right)$ regions.

Models were calibrated using MatLab 7.1 (MathWorks Inc., USA) with the lsqcurvefit function via the trialand-error method to obtain the best statistical results. Statistical analyses of measured and modeled DCAcAm FP data were conducted using MatLab functions, including analytical variance (AV), AV sum of square (AVS) and standard error (SE).

\section{Results and discussion}

Two models, with and without the inclusion of EEM data for the SMP-like and AP-like substances (Table 1), were developed to predict the DCAcAm FP in the Huangpu River source water samples collected from June, 2008 to February, 2010, as shown in Eqs. (2) and (3), respectively. 
Table 1 Raw water quality parameters, and measured and modeled DCAcAm FPs

\begin{tabular}{|c|c|c|c|c|c|c|c|c|}
\hline \multirow[t]{2}{*}{ Year/month } & \multirow{2}{*}{$\begin{array}{l}\text { DON } \\
(\mathrm{mg} / \mathrm{L})\end{array}$} & \multirow{2}{*}{$\begin{array}{l}\text { DOC } \\
(\mathrm{mg} / \mathrm{L})\end{array}$} & \multirow{2}{*}{$\begin{array}{l}\mathrm{Br}^{-} \\
(\mu \mathrm{g} / \mathrm{L})\end{array}$} & \multirow{2}{*}{$\begin{array}{l}\text { SMP } \\
(\mathrm{mV})\end{array}$} & \multirow{2}{*}{$\begin{array}{l}\mathrm{AP} \\
(\mathrm{mV})\end{array}$} & \multicolumn{3}{|c|}{ DCAcAm FP $(\mu \mathrm{g} / \mathrm{L})$} \\
\hline & & & & & & Measured & $\begin{array}{l}\text { Predicted } \\
\text { with EEM }\end{array}$ & $\begin{array}{l}\text { Predicted } \\
\text { without EEM }\end{array}$ \\
\hline \multicolumn{9}{|c|}{ Samples from June 2008 to February 2010} \\
\hline $08 / 06$ & 0.237 & 3.36 & 106 & 359.7 & 477.1 & 1.94 & 1.81 & 2.40 \\
\hline 08/07 & 0.337 & 4.73 & 79.0 & 613.5 & 223.6 & 2.61 & 2.59 & 3.11 \\
\hline 08/08 & 0.296 & 4.29 & 64.0 & 669.7 & 527.5 & 3.71 & 3.51 & 2.88 \\
\hline 08/09 & 0.318 & 3.78 & 107 & 705.2 & 532.6 & 3.95 & 3.46 & 2.90 \\
\hline $08 / 11$ & 0.137 & 4.37 & 115 & 483.7 & 479.4 & 1.58 & 1.84 & 1.72 \\
\hline $08 / 12$ & 0.093 & 4.83 & 96.0 & 541.8 & 503.3 & 1.75 & 1.77 & 1.37 \\
\hline $09 / 02$ & 0.143 & 4.14 & 183 & 529.4 & 290.3 & 1.96 & 1.56 & 1.71 \\
\hline $09 / 03$ & 0.122 & 3.33 & 152 & 440.3 & 376.9 & 1.53 & 1.34 & 1.55 \\
\hline $09 / 04$ & 0.159 & 2.91 & 79.0 & 497.2 & 437.5 & 1.63 & 1.76 & 1.88 \\
\hline $09 / 05$ & 0.207 & 3.95 & 93.0 & 527.5 & 153.7 & 1.72 & 1.52 & 2.24 \\
\hline $09 / 07$ & 0.359 & 4.75 & 82.0 & 681.7 & 264.3 & 2.79 & 3.03 & 3.23 \\
\hline $09 / 11$ & 0.183 & 4.19 & 225 & 503.4 & 463.3 & 1.7 & 1.99 & 1.97 \\
\hline $10 / 01$ & 0.083 & 3.72 & 144 & 449.1 & 343.7 & 1.36 & 1.14 & 1.23 \\
\hline $10 / 02$ & 0.119 & 4.27 & 128 & 482.3 & 326.2 & 1.57 & 1.47 & 1.56 \\
\hline \multicolumn{9}{|c|}{ Samples after February 2010} \\
\hline $10 / 03$ & 0.251 & 3.25 & 131 & 375.5 & 387.5 & 1.82 & 1.71 & 2.45 \\
\hline $10 / 03$ & 0.229 & 3.47 & 117 & 369.5 & 379.2 & 1.77 & 1.66 & 2.34 \\
\hline $10 / 04$ & 0.237 & 3.36 & 95.7 & 372.2 & 267.9 & 1.79 & 1.50 & 2.41 \\
\hline $10 / 06$ & 0.224 & 3.15 & 94.0 & 523.5 & 353.7 & 2.13 & 1.98 & 2.32 \\
\hline $10 / 07$ & 0.292 & 3.65 & 72.0 & 549.7 & 525.2 & 2.97 & 2.88 & 2.81 \\
\hline \multicolumn{9}{|c|}{ Samples from other raw water after February 2010} \\
\hline \multirow[t]{3}{*}{ Yangtze River } & 0.413 & 3.93 & 334 & 351.4 & 213.8 & 1.83 & 1.80 & 2.68 \\
\hline & 0.322 & 3.62 & 296 & 321.5 & 175.3 & 1.38 & 1.48 & 2.52 \\
\hline & 0.357 & 3.27 & 423 & 243.4 & 209.5 & 1.46 & 1.32 & 2.62 \\
\hline \multirow[t]{6}{*}{ Taihu Lake } & 0.873 & 5.75 & ND & 749.5 & 421.3 & 8.57 & 8.97 & 7.44 \\
\hline & 0.895 & 5.33 & ND & 755.7 & 321.5 & 8.24 & 8.04 & 7.52 \\
\hline & 0.835 & 4.57 & ND & 765.1 & 424.1 & 8.76 & 8.28 & 7.13 \\
\hline & 0.526 & 2.43 & ND & 263.5 & 106.3 & 1.55 & 1.63 & 5.13 \\
\hline & 0.733 & 4.35 & ND & 597.3 & 363.5 & 6.15 & 6.17 & 6.55 \\
\hline & 0.675 & 2.99 & ND & 533.7 & 279.2 & 4.23 & 4.43 & 6.07 \\
\hline
\end{tabular}

DCAcAm FP $=0.0077 \times[\mathrm{DON}]^{0.46} \times[\mathrm{DOC}]^{0.32}$

$$
\times\left[\mathrm{Br}^{-}\right]^{-0.085} \times[\mathrm{SMP}]^{0.659} \times[\mathrm{AP}]^{0.38}
$$

DCAcAm FP $=7.236$

$$
\times[\mathrm{DON}]^{0.63} \times[\mathrm{DOC}]^{0.064} \times\left[\mathrm{Br}^{-}\right]^{-0.061}
$$

In Eq. (2), SMP is the most weighted parameter with the highest power ( $b=0.65)$, followed by DON $(e=0.46)$, AP $(f=0.37)$ and then DOC $(c=0.32)$. Interestingly, SMP and AP were the two most significant variables to compute the DCAcAm FP in Eq. (2), in agreement with the finding of a previous experimental study (Chu et al. 2010b) which observed that DCAcAm had a close relationship with SMPlike and AP-like species. In contrast, the power of $\mathrm{Br}^{-}$was close to zero $(d=-0.09)$, suggesting that the presence of $\mathrm{Br}^{-}$does not significantly affect the DCAcAm formation.

Measured DCAcAm FP was compared versus the modeled data from Eqs. (2) and (3) (Table 1) and the corresponding statistical analysis results for the two models (Table 2) showed that the model (AVS 0.01; SE 0.02) containing SMP and AP performed better than the model (AVS 0.59; SE 0.09) without the EEM parameters, for the samples collected from June 2008 to February 2010. Furthermore, when the two models were applied for the Huangpu River samples collected after February 2010, the raw water collected from the Yangtze River (high bromide), and Lake Taihu (high nitrogen), the prediction model with the EEM parameters was still 
Table 2 Statistical analysis results of the models with and without the inclusion of EEM data

\begin{tabular}{|c|c|c|c|c|c|c|c|c|c|c|c|c|c|c|}
\hline Year/month: & 08/06 & 08/07 & $08 / 08$ & $08 / 09$ & $08 / 11$ & $08 / 12$ & $09 / 02$ & $09 / 03$ & $09 / 04$ & $09 / 05$ & 09/07 & 0911 & $10 / 01$ & $10 / 02$ \\
\hline \multicolumn{15}{|c|}{ DCAcAm FP model with the inclusion of EEM data } \\
\hline $\mathrm{AV}$ & 0.265 & 0.004 & 0.050 & 0.120 & 0.170 & 0.015 & 0.202 & 0.120 & 0.081 & 0.115 & 0.091 & 0.173 & 0.155 & 0.063 \\
\hline AVS & 0.257 & & & & & & & & & & & & & \\
\hline SE & 0.273 & & & & & & & & & & & & & \\
\hline \multicolumn{15}{|c|}{ DCAcAm FP model without the inclusion of EEM data } \\
\hline $\mathrm{AV}$ & 0.235 & 0.190 & 0.223 & 0.266 & 0.089 & 0.215 & 0.127 & 0.010 & 0.155 & 0.303 & 0.156 & 0.161 & 0.097 & 0.004 \\
\hline AVS & 0.458 & & & & & & & & & & & & & \\
\hline SE & 0.469 & & & & & & & & & & & & & \\
\hline
\end{tabular}

better than the model without EEM parameters. This suggests that nitrogenous SMP-like and AP-like substances play a significant role in DCAcAm formation.

Although the model with the EEM parameters was acceptable to predict the DCAcAm FP in these waters (AVS $<0.1$; SE $<0.1$ ), the performance was better when it was used for the Huangpu River samples collected after February 2010 (AVS 0.01; SE 0.02) than when used for the samples collected from the Yangtze River (AVS 0.08; SE 0.08) or Lake Taihu (AVS 0.02; SE 0.03). This is because the model coefficients were initially determined using the data of raw water from Huangpu River. Therefore, the DCAcAm predictive model presented in this paper exhibits a degree of specificity to the source water.

\section{Conclusion}

A power function model containing EEM data (SMP and AP) was developed to successfully predict DCAcAm FP of three source waters in China. The important role of SMP and AP in the model suggested that the reduction of nitrogenous SMPlike and AP-like substances prior to chlorination could be an effective treatment strategy to minimize the formation of DCAcAm. In particular, the model suggests that SMP may be a more important precursor parameter to monitor than DON when considering DCAcAm formation, given that the former possessed a higher power in the model than the latter.

Acknowledgments This project was supported by the National Natural Science Foundation of China (51108327, 51178321), International Science \& Technology Cooperation Program of China (2010DFA91800), Postdoctoral Science Foundation of China (20110490073) and State Key Laboratory of Pollution Control and Resource Reuse Foundation (PCRRY11015).

\section{References}

Chen BY, Westerhoff PK (2010) Predicting disinfection by-product formation potential in water. Water Res 44(13):3755-3762

Chen W, Westerhoff P, Leenheer JA, Booksh K (2003) Fluorescence excitation-emission matrix regional integration to quantify spectra for dissolved organic matter. Environ Sci Technol 37(24):5701-5710

Chowdhury S, Champagne P, McLellan PJ (2009) Models for predicting disinfection byproduct (DBP) formation in drinking waters: a chronological review. Sci Total Environ 407(14):4189-4206

Chu WH, Gao NY (2009) Determination of nitrogenous disinfection byproducts chloroacetamides in drinking water by gas chromatography-mass spectrometry. Chin J Anal Chem 37(1):103-106

Chu WH, Gao NY, Deng Y (2010a) Formation of haloacetamides during chlorination of dissolved organic nitrogen aspartic acid. J Hazard Mater 173(1-3):82-86

Chu WH, Gao NY, Deng Y, Krasner SW (2010b) Precursors of dichloroacetamide, an emerging nitrogenous DBP formed during chlorination or chloramination. Environ Sci Technol 44(10): 3908-3912

Chu WH, Gao NY, Templeton R, Yin DQ (2011) Comparison of inclined plate sedimentation and dissolved air flotation for the minimisation of subsequent nitrogenous disinfection by-product formation. Chemosphere 83(5):647-651

Harrington GW, Chowdhury ZK, Owen DM (1992) Developing a computer model to simulate DBP formation during water treatment. J Am Water Works Assoc 84(11):78-87

Huang X, Gao NY, Deng Y (2008) Bromate ion formation in dark chlorination and ultraviolet/chlorination processes for bromidecontaining water. J Environ Sci (China) 20(2):246-251

Imo TS, Oomori T, Toshihiko M, Tamaki F (2007) The comparative study of trihalomethanes in drinking waters. Int $\mathrm{J}$ Environ Sci Technol 4(4):421-426

Krasner SW, Weinberg HS, Richardson SD, Pastor SJ, Chinn R, Sclimenti MJ, Onstad GD, Thruston AD (2006) Occurrence of a new generation of disinfection byproducts. Environ Sci Technol 40(23):7175-7185

Mesdaghinia A, Rafiee MT, Vaezi F, Mahvi A, Torabian A, Ghasri A (2005) Control of disinfection by-products formation potential by enhanced coagulation. Int J Environ Sci Technol 2(4):335-342

Plewa MJ, Muellner MG, Richardson SD, Fasano F, Buettner KM, Woo YT, McKague AB, Wagner ED (2008) Occurrence, synthesis, and mammalian cell cytotoxicity and genotoxicity of haloacetamides: an emerging class of nitrogenous drinking water disinfection byproducts. Environ Sci Technol 42(3):955-961

Richardson SD, Plewa MJ, Wagner ED, Schoeny R, DeMarini DM (2007) Occurrence, genotoxicity, and carcinogenicity of regulated and emerging disinfection by-products in drinking water: a review and roadmap for research. Mutat Res 636(1-3):178-242

Semerjian L, Dennis J, Ayoub G (2009) Modeling the formation of trihalomethanes in drinking waters of Lebanon. Environ Monit Assess 149(1-4):429-436

Sohn J, Gatel D, Amy G (2001) Monitoring and modeling of disinfection by products (DBPs). Environ Monit, Asses 